\title{
Antenatal Diagnosis of Omphalocele
}

\author{
Lt Col PP Som*, Col S Naik, vsm ${ }^{+}$
}

MJAFI 2008; 64 : 276-277

Key Words : Omphalocele

\section{Introduction}

$\mathrm{O}^{\prime}$ mphalocele is an anterior abdominal defect at the base of the umbilical cord, with herniation of the abdominal contents [1]. The etiology of omphalocele is not known. Various theories postulated include failure of the bowel to return into the abdomen by 10-12 weeks, failure of lateral mesodermal body folds to migrate centrally and persistence of the body stalk beyond 12 weeks of gestation. The incidence of the condition is one in 3000 live births [2]. Omphaloceles are associated with other anomalies in more than $70 \%$ of the cases, most of which are chromosomal [2]. The anomaly is detected during routine ultrasonographic (USG) examination of the foetus or during an investigation of increased alpha-fetoprotein (AFP) level. One such case detected by USG is reported.

\section{Case Report}

A 25 year old primigravida reported for routine antenatal ultrasound examination for the first time in the seventh month of pregnancy. There was no contributory family history of any congenital anomaly or spontaneous abortion. Ultrasound shows 27 weeks of gestation. The foetal abdominal scan revealed a $1.5 \mathrm{~cm}$ defect in the anterior abdominal wall in the midline with a mass in the midline protruding through the defect (Fig. 1). The mass had a smooth surface covered by a thin membrane. The content of the mass had the same echotexture as that of the foetal liver, which herniated through the central abdominal defect. The umbilical cord was attached to the apex of the herniated mass (Fig. 2). No foetal ascites was seen. There was moderate polyhydramnios. No other anomaly was noted in the foetus. A diagnosis of omphalocele was made and pregnancy was terminated. Post operatively the diagnosis was confirmed (Fig. 3).

\section{Discussion}

Physiologic umbilical herniation occurs during the eighth week of development when the fetal midgut extends into the extraembryonic celom, occupying the proximal segment of the umbilical cord. The bowel undergoes a 270 degree counter clockwise rotation, the first 90 degree of which occurs by week 10 , extracoelomically at the base of the umbilicus. The remaining 180 degree clockwise turn occurs after the bowel returns to the abdomen. Rotation occurs around the axis of the superior mesenteric artery. The midgut returns to the abdominal cavity at 12 weeks of menstrual age. One of the theories regarding the causation of omphaloceles is failure of the bowel to return to the abdomen [3].

Associated anomalies are common (45-88\%) and their severity determines the prognosis. The chromosomal anomalies (40-60\%) include trisomies 18, 13 and 21, Turner, Klinefelter and triploidy syndromes. The cardiac, genitourinary, gastrointestinal, musculoskeletal, neural tube and head neck defects with Beckwith-Wiedemann syndrome may also be present. It is thought that a chromosomal anomaly is more likely when oligohydramnios or polyhydramnios complicates the pregnancy. It has been reported that omphaloceles containing only bowel have a higher incidence of karyotypic abnormalities [4]. One recent study [5] has shown that periconceptional multivitamin use is associated with a $60 \%$ reduction in the risk of nonsyndromic omphalocele. The mortality rate is $80 \%$ when associated anomalies are present and it increases to $100 \%$ when chromosomal and cardiovascular anomalies are present. The size of the omphalocele does not affect prognosis. The male-to-female ratio is $1: 1$.

Ultrasonography is the imaging modality of choice for the prenatal assessment of the foetus. The earliest that an omphalocele can be detected is at 12 weeks of menstrual age. Magnetic resonance imaging (MRI) facilitates perinatal management and parental counseling [6]. An omphalocele is diagnosed on USG when a fetal anterior midline mass consisting of abdominal contents that have herniated through a midline central defect at the base of umbilical insertion is demonstrated. The mean

*Graded Specialist (Radiodiagnosis), 158 BH, C/o 99 APO. ${ }^{+}$MHA (AIIMS), CO, SFF Hospital, HQ Establishment No 22, C/O 56 APO. 


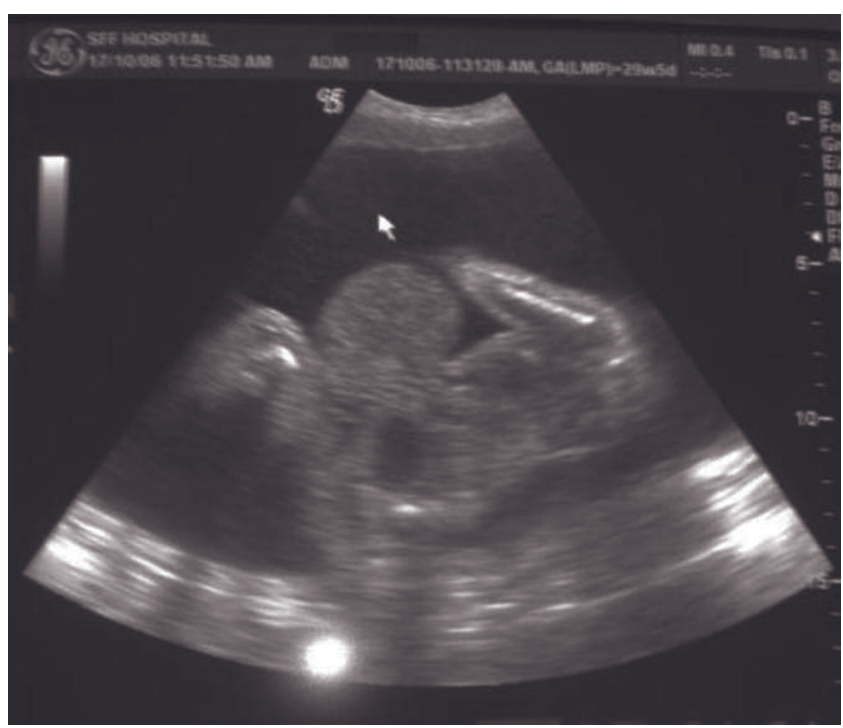

Fig. 1: Antenatal ultrasonography showing a midline mass protruding through a central anterior abdominal wall defect.

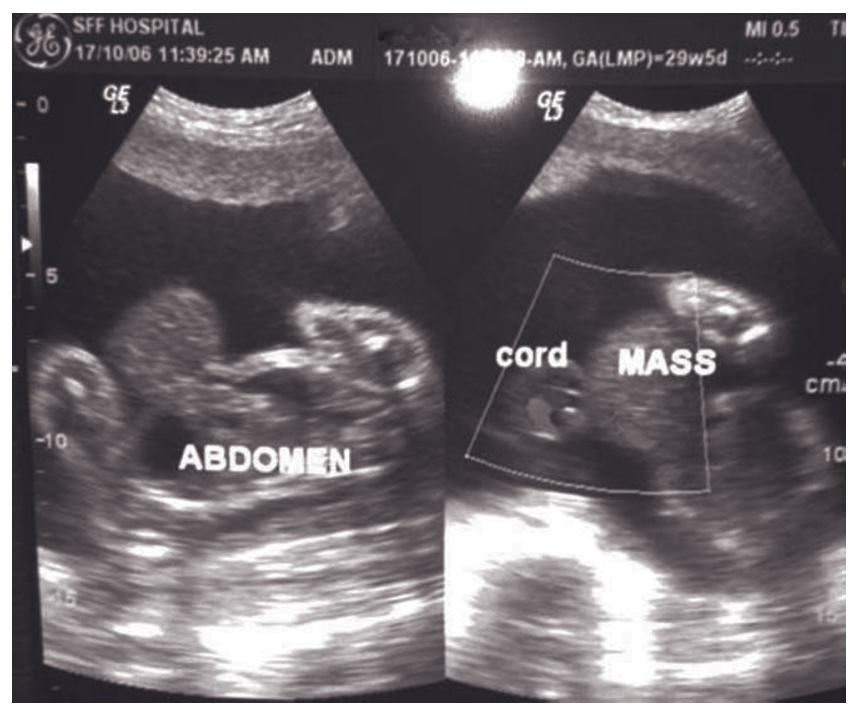

Fig. 2 : Ultrasonography and doppler scan showing umbilical cord attached to the apex of the herniated mass.

size of the defect is $2.5-5 \mathrm{~cm}$, with fetal ascites. Polyhydramnios, and occasional oligohydramnios with associated anomalies are common [7]. A physiologic hernia seldom exceeds $7 \mathrm{~mm}$ in diameter or rarely persists after 12 weeks of gestation.

Other major differential diagnosis is Gastroschisis, with herniation of the bowel through a small, off midline abdominal wall defect. This herniation protrudes into the amniotic cavity usually in the right paraumbilical region. No covering membrane is present. Gastroschisis is thought to result from a vascular event of the omphalomesentric artery [8]. Affected patients have malrotated bowel. Vascular compromise may occur from a volvulus, and it may result in bowel obstruction, ischemia or atresia. Besides malrotation, gastroschisis is not associated with other anomalies. Affected patient

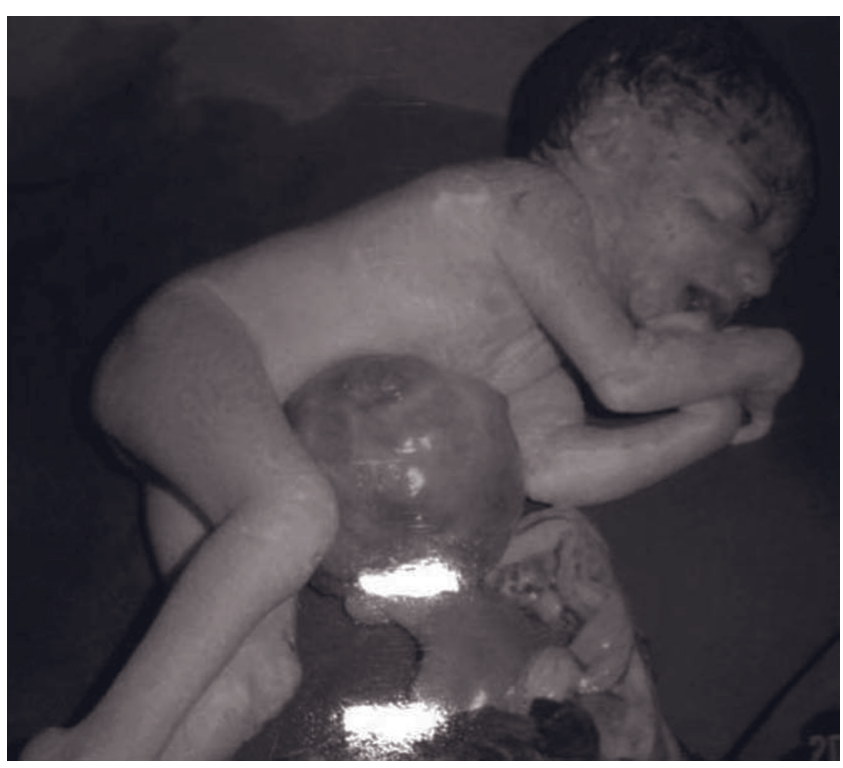

Fig. 3 : Post-operative picture showing omphalocele.

karyotypes are normal. The prognosis is favorable.

\section{Conflicts of Interest}

None identified

\section{References}

1. F Gray Cunningham, Norman F Grant, John C Hauth. Ultrasound and Doppler. In : F Gray Cunningham, editor. Williams Obstetrics. $21^{\text {st }}$ ed. United States of America: Mc Graw-Hill, 2001; 1126-7.

2. Jo-Ann M, Johnson, David A Nyberg. Chromosomal Abnormalities. In : Carol M Rumack, Stephanie R Wilson, J William Charboneau, editors. Diagnostic Ultrasound. $2^{\text {nd }}$ ed. St. Louis : Mosby, 1998; 1192-3.

3. Jack Abrahamson. Hernias. In : Michael J Zinner, Seymour I Schwartz, Harold Ellis, ed. Maingot's Abdominal Operations. $10^{\text {th }}$ ed. United States of America : Prentice Hall International Inc, 1997; 529-30.

4. Vasudevan PC, Cohen MC, Whitby EH, Anumba DO, Quarrell OW. The OEIS complex : two case reports that illustrate the spectrum of abnormalities and a review of the literature. Prenat Diag 2006; $26: 267-72$.

5. Botto LD, Mulinare J, Erickson JD. Occurence of Omphalocele in relation to maternal multivitamin use; a population based study. Pediatrics 2002;109 : 904-8.

6. Mc Mahon CJ, Taylor MD, Cassady CI, Olutoyee OO, Benzold LI. Diagnosis of pentalogy of Cantrell in the fetus using magnetic resonance imaging and ultrasound. Pediatric Cardiology 2007; 28 : 172-5.

7. Anandakumar C, Nuruddin Badruddin M, Chua TM, Wong YC, Chia D. First-trimester prenatal diagnosis of omphalocele using three-dimensional Ultrasonography. Ultrasound Obstet Gynecol 2002; $20: 635-6$.

8. Wu JL, Fang KH, Yeh GP, Chou PH, Hsieh CT. Using color Doppler sonography to identify the perivesical umbilical arteries: a useful method in the prenatal diagnosis of omphalocele-exstrophy-imperforate anus-spinal defect complex. J Ultrasound Med 2004; 23 : 1211-5. 